Research Article

\title{
WeChat-Based Interactive Translation Mobile Teaching Model
}

\author{
Fachang Wang $\mathbb{D}$, Qingling Wang, and Cuifang Du \\ Weifang Engineering Vocational College, Qingzhou 262500, Shandong, China \\ Correspondence should be addressed to Fachang Wang; 2008020107@st.btbu.edu.cn
}

Received 13 September 2021; Revised 8 October 2021; Accepted 25 November 2021; Published 22 December 2021

Academic Editor: Sang-Bing Tsai

Copyright $(2021$ Fachang Wang et al. This is an open access article distributed under the Creative Commons Attribution License, which permits unrestricted use, distribution, and reproduction in any medium, provided the original work is properly cited.

\begin{abstract}
Although the research results of mobile teaching mode at home and abroad have been involved in all aspects of education and teaching and provided a lot of useful reference for subsequent researchers, the lack of research on WeChat interactive translation teaching mode makes the practical research in this field urgent. As China's education industry continues to pursue international development, it is necessary to train a large number of international talents who have an international perspective, are familiar with international rules, and can participate in international affairs and international competition. However, to become an international talent, you must first have superior English communication skills and be able to deal with various international situations proficiently. The English education goals at the basic education stage are simply beyond reach and can only be cultivated through professional and systematic college English courses. This shows that college English education is at a crucial position in the future development of education. This study attempts to explore how to apply the interactive teaching mode supported by WeChat network platform in translation teaching and English learning of high school students, so as to improve students' autonomy in translation practice, promote students' personalized learning, and improve students' interest and ability in English learning. Based on the investigation of a senior high school in our city, the school began to implement the interactive translation mobile teaching mode based on WeChat in September 2018. The experiment selected the change of students' English learning achievements in a certain semester and judged whether the mobile teaching mode was conducive to the improvement of learning performance based on $t$-test. We also need to collect the needs of teachers and parents for the WeChat based mobile teaching mode and judge whether the mode can be promoted. The experimental results show that this teaching mode has an obvious effect on the improvement of students' English scores, especially in the eighth grade, whose scores have increased from 72.6 to 75 . Through the construction of WeChat based interactive translation mobile teaching mode, parents can fully understand the key points of English learning and make English tutoring more targeted and timely. This teaching mode is worthy of promotion in senior high school English course learning.
\end{abstract}

\section{Introduction}

1.1. Background and Significance. College English teachers should closely follow the pace of development in the Internet era, pay attention to the improvement of their own information technology literacy, and rationally integrate educational technology into classroom teaching practice: encourage teachers to build and use micro-classes and WeChat and use online high-quality educational resources to transform and expand the teaching content and implement the mixed teaching mode such as flipped classroom based on classroom and online courses, so that students will develop towards active learning, independent learning, and personalized learning. In the era of rapid dissemination of
Internet information, mobile teaching mode has brought a lot of convenience to students. As one of the providers of mobile learning resources, WeChat has become a research hotspot. However, the problems faced in actual college English education are as follows: first, the number of college English teachers is limited, and college English generally adopts the traditional method of teaching in large classes; second, students have complex professional backgrounds, and their English proficiency is even more uneven, and teachers cannot take into account the development of each student's English level. In recent years, many colleges and universities have also tried to reform college English courses, such as flipped classroom teaching mode, micro-class teaching mode, and mixed teaching mode, most of which are 
completed through online course learning platforms to complete resource sharing and learn. As a learning tool, WeChat can be widely used in universities, professional colleges, and primary and secondary education. For example, in the interactive translation mobile teaching, the model can fully consider the individual differences of students and achieve good teaching effect and teaching level. WeChat is regarded as a superportal, which is instant, interactive, and effective. Therefore, the construction and application of WeChat based interactive translation mobile teaching mode are of great significance to teaching. Online schools simply connect online and offline classroom learning. It is still quite difficult for teachers to manage and monitor students. There is no substantial change in the interaction between teachers and students, and between students and students. With the popularization of mobile terminal smart phones, students are hand-to-machine, and they usually do not leave their bodies. The phenomenon of looking down at mobile phones in class is more common. Therefore, researchers have compared and analyzed the advantages and disadvantages of flipped classrooms and online teaching models and used mobile phones to assist teaching.

1.2. Related Work. The main content of college English teaching in colleges and universities is divided into three parts, general English, special purpose English, and crosscultural communication English. In addition, college English courses are mainly composed of three types: compulsory courses, limited elective courses, and optional elective courses. The college English courses involved in this study are general English courses that are required or optional for non-English majors in undergraduate colleges and universities. The purpose of this study was to investigate the cognition, attitude, and status of preservice teachers using iPad during their professional study and school practice. So, we conducted experiments involving 117 preservice teachers with one-year postgraduate qualification in the UK. The mixed method was used to design the experiment, and the data were collected through questionnaire survey as well as group-group [1]. Many researchers have proved the effectiveness of educational games in the field of learning. Because of the new wave of mobile technology, these games can even run on mobile devices. Zhang introduced a new mobile educational game designed to teach computer architecture. In particular, different learning methods are realized in this game, so that students can learn the course of this topic in an interesting way [2].

Despite the encouraging achievements of statistical machine translation and, more accurately, neural machine translation systems in the past few years, the technology is still not perfect. The output of machine translation system must be corrected by artificial intelligence machine in the later editing stage. Interactive protocols promote human-computer collaboration to improve productivity. In this work, HuR integrates neural machine translation into an interactive machine translation framework. In addition, HuR proposed a new interaction protocol to provide users with better experience and higher productivity [3]. The traditional machine translation method uses the order from left to right, so it is difficult to modify the key errors at the end of sentences directly. In this experiment, Sanchez Garcia proposed an interactive machine translation framework. In this framework, interaction is decomposed into two simple human behaviors, namely, key translation errors and translation modifications. The selected phrase can be located in any position of the sentence, which improves the efficiency of human-computer interaction. Sanchez Garcia also proposed two kinds of behavior automatic suggestion model to further reduce the cost of human-computer interaction [4]. Before designing the research path, we must first sort out the relationship of the three main roles in the research, namely, students, teachers and technology. In ancient and modern times, the main purpose of education is to educate people, and whether it is the teaching design of teachers or the emerging educational technology, it is to promote the learning and development of students. Obviously, students are the main body of the classroom. Teachers are a kind of profession. The main task is to teach and solve puzzles. It plays a leading role in the education process and educators and leads the students' physical and mental development in an all-round way.

1.3. Innovation. The innovation of this study lies in the following: first, the more scientific statistical methods and analysis software are used for quantitative research, and the data are authentic and reliable. Second, the research topic is the mobile teaching mode based on WeChat. This teaching mode represents the future development direction of research teaching to a certain extent. However, the understanding of mobile teaching mode is still superficial and has an important research value. Based on the opportunity of the university's college English curriculum reform, this research starts from the current status of college students' English learning, integrates a variety of information technologies, and designs the teaching model on the basis of deep learning and related theoretical explorations to improve college students' English synthesis ability and basic literacy, to achieve the purpose of promoting the deep learning of college students' English, in the hope of providing reference for related research.

\section{Construction and Application of Interactive Translation Mobile Teaching Mode Based on WeChat}

2.1. Rational Analysis Framework Model of Mobile Teaching. In the rational analysis model of mobile teaching, people think that mobile teaching experience takes place in the framework of informatization. Students study independently or cooperate with each other, using and creating information [5]. Interactive information is transmitted through technology. After complex interaction, information becomes extremely rich. In this case, the model uses Venn diagram to describe the relationship and significance between three different levels and their intersection points in mobile teaching [6]. These three levels are equipment, students, and society. 
2.1.1. Equipment Level. Device level refers to the physical, technical, and functional characteristics of mobile devices, including the input/output functions and internal programs of the machine, such as storage capacity, power, processor speed, compatibility, and scalability. These characteristics come from the design of hardware and software, which have an important impact on the user's comfort. Since the mobile phone provides an interface between students and learning, it is extremely important to evaluate these features. As a bridge between people and technology, the design of equipment must maintain a high degree of physiological and psychological comfort [7]. In other words, the characteristics of the device can significantly affect its use. For example, the characteristics of portable devices must meet the normal physiological and psychological conditions of individual users, such as size, weight, structure, and composition; especially, the input/output function should be suitable for human perception and motor function. Similarly, the memory capacity and speed of devices and processors, file storage, and file exchange require a certain error free response rate, and the response rate will be adjusted over time to meet user expectations $[8,9]$. With a well-designed mobile device, users can focus on cognitive tasks rather than the device itself [10].

2.1.2. Learner Level. The level of learners includes personal cognitive ability, memory, previous knowledge level, and emotional status, which play an important role in how learners use existing knowledge and how to encode, memorize, and transmit information [11]. This level also summarizes the theories related to knowledge transfer and self-discovery learning. Students' knowledge level, enthusiasm, and emotional state have a significant impact on the encoding, memory, and transmission of information. According to the actual situation, it is an effective teaching method to actively select or plan learning activities and encourage students to find rules in the real and cultural environment. By enabling students to obtain various forms of information, highlighting the background and purpose of information, mobile learning helps strengthen the recovery and transmission of information $[12,13]$.

2.1.3. Social Level. Social dimension includes the process of social interaction and cooperation. In order to exchange information, acquire knowledge, and continue cultural activities, people must follow the rules of cooperation [14]. The rules of cooperation are determined by the cultural background of the students or the cultural background of the exchange area. In mobile learning, this culture can be real or virtual [15]. It is important to realize that the participants in the dialogue are constrained by certain conditions. These limitations provide guidance and methods for promoting communication. When joining a new group, you must share your "signaling system" and learn from it. Cooperative dialogue requires that the information provided is necessary, accurate, relevant, and clear enough [16]. Failure to comply with one or more of these rules may result in communication barriers. Participants may also deliberately violate the rules of procedure and practice in order to achieve certain goals. It is important that participants in the dialogue pay attention to each other, identify communication problems, and make appropriate explanations. Through interaction, people get feedback, which in turn reinforces social and cultural beliefs and behavior.

2.2. Constructivism Model. Constructivism is not a specific teaching strategy. On the scientific level, it is a cognitive learning model. This paper mainly discusses how to understand the essence of knowledge [17]. It does not emphasize learning, but students communicate and discuss dialectically with teachers, constantly checking the knowledge they have learned, so as to reflect and explore the gap between new knowledge and new knowledge and further assimilate the process.

Creating a good learning environment for students should include four aspects: creating a good learning environment, collaborative construction, communication construction, and meaning construction. In fact, students' learning process not only needs to accept new knowledge, but also needs to test and criticize new knowledge [18]. The constructivist model also emphasizes the subjectivity of students and thinks that students are not only receiving knowledge from teachers. In this process, students should also use necessary materials or other learning tasks with the help of peers and teachers to achieve the goal of knowledge construction independently $[19,20]$. Students' knowledge construction is not passive, but active. This kind of knowledge can only be mastered by students themselves and cannot be replaced by others. Teachers play the role of supporter, cooperator, and guide in the learning process [21]. While guiding students to establish knowledge, teachers should fully consider the existing learning experience of students, should not ignore the connection between new and old knowledge, and guide students to construct knowledge better on the basis of preliminary learning experience.

Constructivism claims that knowledge is produced through the interaction and discussion between individuals and others; that is, individuals must interact and discuss with others constantly, while others are subjectively adapted to the knowledge constructed by individuals. The process of learning starts from an external environment and transforms the external experience into an internal psychological process, namely, internalization. In other words, the process of interaction between human and society is the process of transforming experience into internalization [22]. Therefore, teachers should guide students to create new social knowledge, or fill in the deficiency of personal previous knowledge, and use cooperative learning and group discussion teaching mode. On this basis, constructivism teaching is different from the traditional teaching methods. Students no longer passively accept the information provided by teachers. They must actively explore and establish knowledge, and students must be responsible for their own learning attitude. 


\subsection{Construction of Mobile Learning Mode}

2.3.1. Learner Characteristics. Students are the main body of mobile learning activities. Before learning activities, we must analyze the characteristics of students. The different situations of students determine whether the learning activities can be carried out smoothly [23]. Students of different ages have different personality characteristics, so it is necessary to fully understand students' learning psychology and analyze their learning style and learning environment [24]. In addition, teachers must focus on the analysis of students' cognitive ability and cognitive structure variables to determine the existing cognitive structure and related knowledge of students. In order to carry out learning and communication smoothly, they must also consider the use and installation of students' mobile WeChat app equipment.

2.3.2. Course Objectives. Curriculum objective analysis is the second step in the demand analysis stage, which plays an important role in mobile learning activities. Before planning learning activities, a detailed analysis of the course is required [25]. On the premise of fully understanding the content of the course, analyze the importance of this course in each chapter, so as to continue to analyze the objectives of the course. Learning activities are guided by the curriculum objectives, and the teaching process is designed to achieve the curriculum objectives [26].

2.3.3. Learning Content. Before planning mobile learning activities, it is necessary to analyze not only the course objectives, but also the learning contents. Learning content analysis is an important part of mobile learning activity planning; not all knowledge can be applied to mobile learning. When designing learning content, teachers must fully consider the learning environment, students' learning needs, and the characteristics of mobile learning [27]. The learning content of M-learning is mostly declarative, and the knowledge unit is as short as possible, but at the same time, it must be ensured that it is a complete comprehensive knowledge unit. Different and diverse forms of learning content can effectively improve students' learning enthusiasm [28]. When designing the course content, teachers should also pay attention to students' reading experience, printing design, image selection, text color, etc., which must conform to the learning style of students and think about how to display the course content appropriately and gracefully.

\section{Construction and Application of WeChat- Based Interactive Translation Mobile Teaching Mode}

3.1. Research Object. The experimental object is a senior high school in our city, and the research on the practice of interactive translation mobile teaching mode based on WeChat in English discipline is carried out. Since September 2018, the teaching practice has lasted one semester since the data collection, which is the first semester of grade seven, grade eight, and grade nine.
3.2. Experimental Content. Teachers will arrange the courseware, syllabus, pictures, voice and video and other teaching materials, and, according to the teaching progress, timely transfer to WeChat. Release the teaching objectives, key points, difficulties, and important problems of each class before class. All teachers in the research group prepare lessons collectively before class and carefully design relevant problems and problem scenarios according to the teaching content and students' characteristics, which can arouse students' interest in inquiry and guide students to preview. In class, WeChat is used to detect and discuss the students' preview and classroom learning, find problems and teaching difficulties, adjust teaching in time, summarize important teaching contents, arrange assignments, and solve difficult problems after class, so as to achieve the purpose of reviewing, consolidating, and expanding knowledge. In autonomous learning, students can freely arrange the time and place to enter the WeChat platform to browse teaching resources. They can also look up relevant materials on the Internet for preview and find the answers to the questions. Students can use the functions of group chat and video and audio in WeChat to discuss and communicate with classmates or teachers about a certain teaching content after class. When teachers ask questions in class, each student can publish the answers through WeChat platform, which can ensure that each student actively thinks about the problem and participates in the interaction between teachers and students, so that teachers can better grasp the students' understanding of knowledge.

The way to develop teaching methods is that teachers assign homework after class, and students finish the homework assigned by teachers on time after class and share the results of oral reading and English translation homework in WeChat group after taking photos. Parents and teachers cooperate to urge students to complete the progress of homework and upload it to WeChat. The teacher can know the students' homework in real time after class and adjust the class content of the next day according to the students' homework completion. The experiment needs to establish two WeChat groups: one is a group of students, including teachers and students, used to release homework at home and daily order management of the class. Students can discuss learning related problems with their teachers in this group. The other is the parent group, including teachers and students' parents. Teachers release homework and answers through the parent group. After students' homework is completed, parents are informed to use the parent account to check the answers, so as to ensure that parents can exercise effective supervision. At the same time, parents can contact teachers through the parent group to exchange the latest student status and feedback students' problems.

3.3. $T$ Test. The $t$-test uses the distribution theory $t$ to determine the probability of difference and compares whether the difference between the two means is significant. Double sample $t$-test is a kind of $t$-test, which refers to the data obtained from two tests on the same sample or two data sets obtained by testing two complete samples under different 
conditions. If the total average value has significant difference, $t$-test method is adopted in this experiment. $T$-test depends on the homogeneity of variance; that is, the homogeneity test of variance is conducted first to determine whether the difference between the two samples is the same. The formula of homogeneity test of variance is

$$
F=\frac{S_{1}^{2}}{S_{2}^{2}}
$$

If the $F$ value is less than the critical value of the test results, the changes of the two samples should be equal, and the $t$-test can be used directly. If the $F$ value is greater than or equal to the critical value of variance homogeneity test results, the two sample populations are not equal. $T$-test can be used to test. The formula of paired sample $t$-test is as follows:

$$
\begin{aligned}
s_{d} & =\sqrt{\frac{\sum d^{2}-\left(\left(\sum d\right) / n\right)^{2}}{n-1}}, \\
t & =\frac{\bar{d}}{s_{d} / \sqrt{n}} .
\end{aligned}
$$

After calculating the $T$ value, refer to the $t$-test critical value allocation table to determine the size of the two values to determine whether there is significant difference. If the absolute value of the test statistic $t$ is less than the critical value in the $t$-test table, there is no significant difference in the mean value between the two populations. If the absolute value of the statistical test value $t$ is greater than or equal to the critical value in the distribution table of the critical value $t$-test value, the average value of the two populations has significant difference.

\section{Construction and Application Experiment Analysis of Interactive Translation Mobile Teaching Mode based on WeChat}

4.1. T Test Results of Students' Average Score. Some people even say that the status of teachers in the classroom is threatened. This view is obviously nonsense. Information technology can add fun to the classroom, help teachers explain, help students understand, record students' learning data, assist teachers to supervise and understand each student's learning behavior, and carry out various teaching activities. It can be seen that technology in the classroom is mainly to assist teachers to teach and students to learn.

As one of the ways of language output, English translation is an important part of English learning. English translation learning and teaching cannot be separated from the basic vocabulary, sentence pattern, text organization, and other elements, which are also the criteria for judging the level of translation. No matter these are English majors or non-English majors, their English foundation needs to be strengthened. The elements of English translation include content, vocabulary, grammar, text layout, and application standardization. In practical teaching, the emphasis is on the input of words and sentence patterns to improve students' sense of language so as to complete the correct language output. The average score of English subjects in the last semester of the class without teaching practice was taken as the initial level and compared with the English performance data of three grades of WeChat interactive translation mobile teaching practice. The statistical results are shown in Table 1.

From the $t$-test results, we can see that the results of WeChat based interactive translation mobile teaching model have an obvious upward trend in the three grades, which shows that the teaching mode is conducive to the improvement of learning performance. The $T$ value of Grade 7 is the largest, which is 2.247 , followed by grade 8 with $t$ value of 1.526 , and grade 9 with the minimum value of 0.21 .

This research follows the paradigm of design research and has gone through two rounds of iterative design process. First of all, by reading the literature related to college English teaching, communicating with frontline teachers and listening to classes discover the common problems in them and analyze the main reasons for the problems; secondly, study a lot of relevant literature on mobile learning and college English teaching models and carry out a review to explore the integration points of deep learning and college English teaching models.

The new teaching mode based on WeChat mainly uses the group sending function, voting management function, and user-defined menu function of WeChat. In the actual teaching, according to the teaching objectives and needs, these functions are flexibly embedded into the teaching process inside and outside the class. In this study, the interactive translation mobile teaching mode based on WeChat is student-centered, which is quite different from the traditional teaching mode in the aspects of preview before class, review after class, and learning evaluation, so as to give full play to the role of modern educational technology in improving practical teaching. The application of WeChat in teaching is mainly in three aspects: preview before class, review after class, and knowledge evaluation. In addition, some students, out of their interest in the course itself, understand and learn the course content displayed by WeChat through the introduction of peers or teachers, so as to meet students' personalized learning needs and realize personalized mobile learning.

As shown in Figure 1, the score changes of students in different grades are presented. The English subject level of the three grades has been improved. The grade 7 students' average score increased from 75.6 in the first class to 76.2 in the later grade. The change of grade 9's score was similar to that of Grade 7. The range of Grade 8 students' score was 72.6 to 75 , and the effect of performance improvement was the most obvious. Mobile learning based on WeChat can carry out multilevel interaction, strengthen the communication and communication between teachers and students, and enrich students' learning experience. In the learning process, it is divided into two stages: before class and after class. Before class, the teacher will release the tasks that students need to complete through WeChat platform according to the teaching objectives. Students can preview before class and find solutions to the problems raised by 
TABLE 1: T-test results of student average score.

\begin{tabular}{lccc}
\hline Grade & Seventh grade & Eighth grade & Ninth grade \\
\hline Class average score & 75.6 & 72.6 & 80.1 \\
Grade average & 76.2 & 75 & 80.6 \\
$T$ value & 2.247 & 1.526 & 0.210 \\
\hline
\end{tabular}

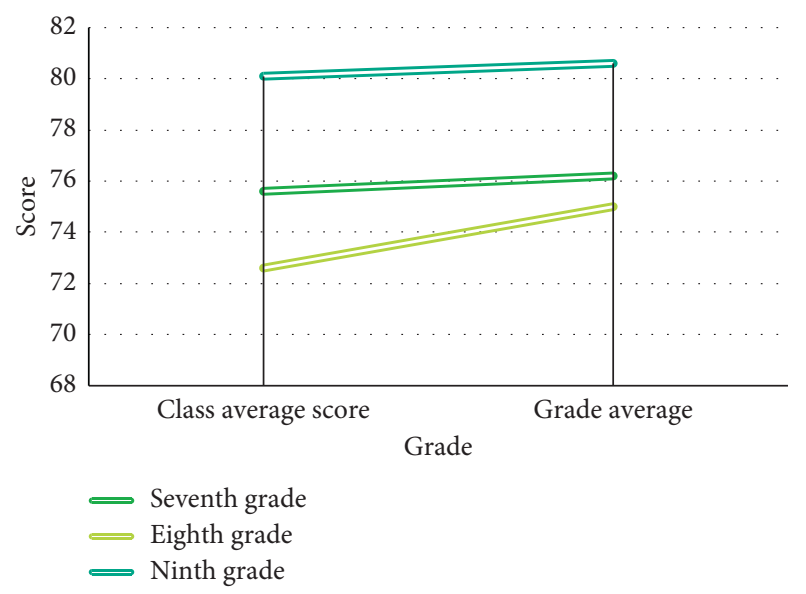

Figure 1: Changes of students' scores in different grades.

teachers. In this process, students can share the content with teachers, other students, WeChat group, circle of friends, etc. After class, the teacher will post the exercises and detailed explanations related to this class to WeChat, and students will conduct self-test to promote students' consolidation and understanding of knowledge. In addition, teachers also provide students with expanded knowledge related to teaching content through WeChat platform to enrich students' knowledge.

4.2. Self-Evaluation of Students' Self-Study Before Class. Before carrying out this teaching practice activity, it is necessary to evaluate the students' self-study, self-evaluation, and analysis. In the self-evaluation results of students' self-study before class, most students think that they have higher enthusiasm before class, and the corresponding is that the students with higher self-learning enthusiasm have better self-study effect, and the self-evaluation results of the two are consistent. Overall, however, students' self-learning achievement is worse than that of preclass self-study, which may be related to the higher self-demand of students, the large number of learning resources, and the difficulty of preclass tasks, as shown in Figure 2.

Students are accustomed to the traditional classroom learning method passively and step by step under the teacher's "arrangement," lacking the spirit of autonomous learning. Therefore, after the initial freshness disappears, students will begin to get tired of the way that they need to spend several times more time learning and even passively deal with the learning of teaching videos. Over time, the mobile teaching mode has lost its charm among students. Students' negative burnout is also easy to cause trouble to teachers, and finally teaching practice has become a mere formality teaching mode. Therefore, when teachers practice the mobile teaching mode, on the one hand, they should make the students realize that the mobile teaching mode is not a set of fancy. They should not simply understand it as learning with mobile phone WeChat, nor blindly follow the flow. In order to cope with the existing examination system, they should flow into the form. On the other hand, teachers should constantly urge students to study on WeChat platform and keep their learning enthusiasm, so as to make students have a positive attitude towards the mobile teaching mode based on WeChat.

4.3. Team Cooperation. English learning is a meaningful process of complex cognitive processing and processing. Its essence is the construction process of interaction between structured knowledge and nonstructured knowledge; it requires learners to activate original knowledge, recall memory, and combine new knowledge and new information, as well as analysis, integration, migration, and creation of new problems. Deep learning has changed the current status quo of middle- and low-level thinking goals in teaching, such as memorization, comprehension, and application, and aims to promote the development of learners' higher-level thinking.

Learning input mainly refers to the learning efficiency, psychological expectation, and effort level of students in the whole learning process. Therefore, the quality of the learning process and the evaluation of learning results will be restricted by students' learning input. Teachers and schools will increase and improve students' learning input as a common goal when conducting curriculum reforms. Behavioral input, cognitive input, and emotional input together constitute the three dimensions of learning input theory, among which behavioral input is the explicit representation of learning input. In the aspect of group cooperation, there are two kinds of larger differences between students' degree of group cooperation and their own contribution to the group. On the one hand, less than half of the students are satisfied with the degree of group cooperation. Most students think that the group cooperation and communication need to be further deepened; especially nearly half of the students think that the communication situation in group activities is general. On the other hand, most students think that their contribution to the group activities is high, and less than half of the students feel that their contribution to the group is not enough. The results show that the degree of their contribution to group activities does not match the degree of group cooperation. When students feel that they pay more for the group activities, the cooperation of the group is not satisfactory. It may be related to the low enthusiasm of individual members in the group and the dependence on other members of the group, or the task arrangement of the group is not reasonable enough to allow students to fully cooperate with each other. The situation of group cooperation is shown in Figure 3.

The application of students' deep learning strategy is positively correlated with deep motivation, the application of shallow learning strategy is positively correlated with 


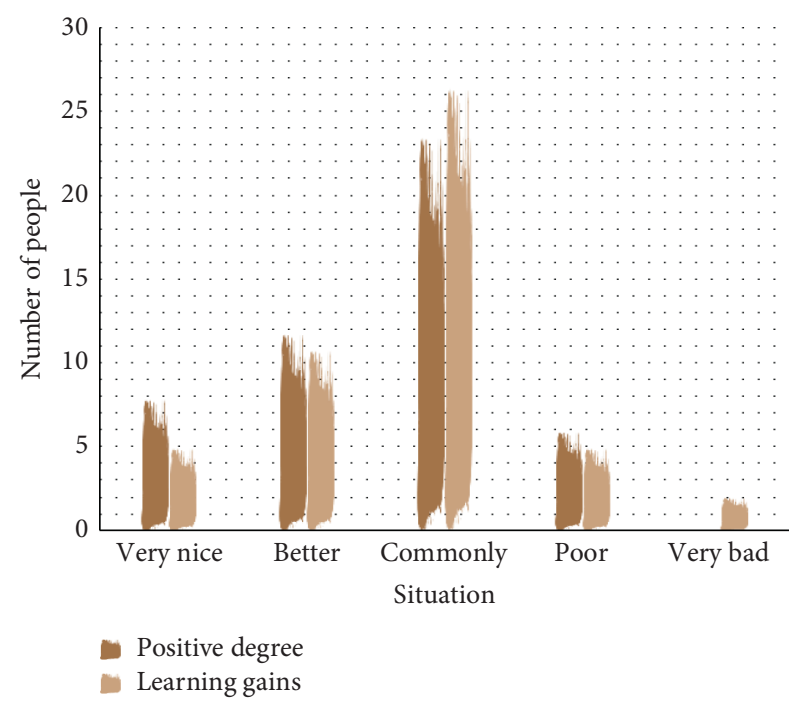

FIgURE 2: Self-evaluation of students' self-study before class.

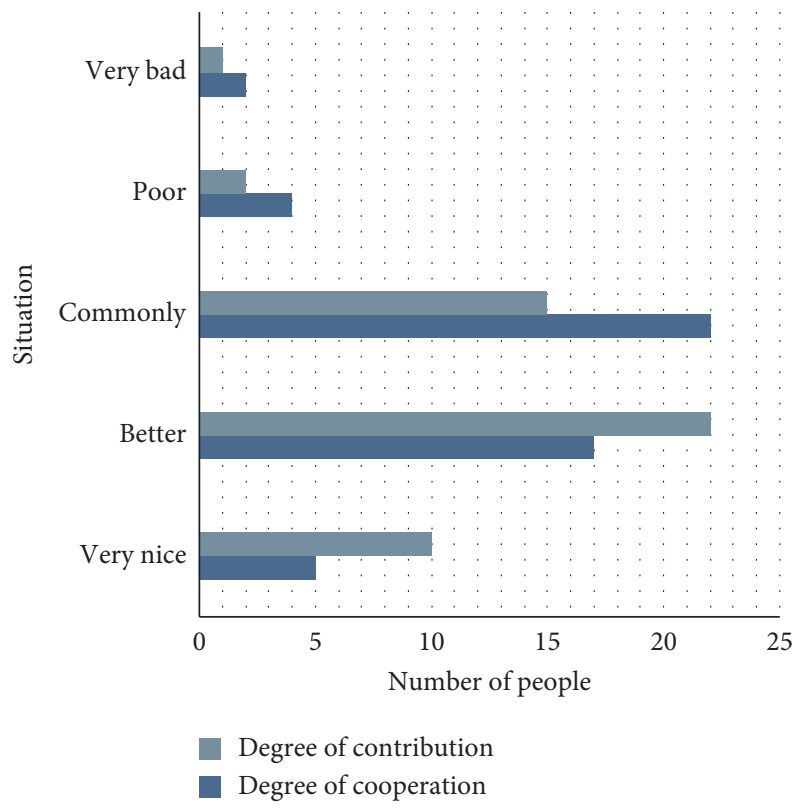

Figure 3: Group cooperation.

superficial motivation, and deep motivation is negatively correlated with superficial motivation. The Undergraduate Learning process scale is an effective tool to assess whether undergraduates have achieved deep learning results in the learning process. Therefore, researchers have been inspired by it. Empirical research on deep learning can start with measuring students' learning motivation and learning strategies and evaluate whether students have deep learning results in the learning process.

The mode of learning makes most students feel that they have a good grasp of basic knowledge, but the actual results are not very ideal. On the other hand, some students' English foundation is weak, so it is more difficult to improve their English performance, and the ability of self-correction is even more difficult.
4.4. Analysis of Parents' Needs. There is a significant correlation between learning input and deep learning. When students have a high learning input in the course of learning, they will apply deep learning strategies, and the goal of deep learning will be achieved. Therefore, when researchers are designing teaching models, they can use mobile learning media to increase students' preclass behavioral investment, classroom behavioral investment, and after-class behavioral investment in college English courses, further affecting emotional investment and cognitive investment and, thus, promoting the deep learning of college students' English. Let' us explore the relationship between deep learning and learning strategies in detail.

First of all, through the construction of WeChat based interactive translation mobile teaching mode, parents can fully understand the key points of English learning and make English counseling more targeted and timely. The collected data show that many parents are willing to give more help to students in English learning after they realize the importance of English learning, but they have no place to start. Through the display of WeChat platform, parents can learn more about the dynamic of English test, so that parents' English guidance is more targeted. Secondly, through the WeChat platform, parents can understand the school dynamics of students. Adolescent high school students, physical and mental development is in a sensitive rebellious period, less communication with their parents. Through WeChat platform, parents can make the dynamic of school English curriculum clear, understand the law of physical and mental development of senior high school students, change the concept of education, and change the mode of education, so as to promote the healthy development of high school students' body and mind.

In the teaching practice of the iterative cycle, we continuously optimize and improve the constructed flipped classroom framework through reflection, summary, and data feedback and finally form a perfect flipped classroom design model. The flipped classroom that promotes deep learning can enhance the interpersonal interaction between teachers and students in the classroom and enhance the students' sense of participation in the curriculum; at the same time, it can improve students' understanding and promote the development of deep learning cognitive ability.

As shown in Figure 4, parents of senior high school students have the needs of understanding junior high school English counseling, understanding senior high school students' English learning dynamics, understanding senior high school students' physical and mental characteristics, and paying attention to school related notices. Parents are most concerned about the needs of English tutoring, accounting for 31\%, followed by English related learning dynamics, accounting for $26 \%$. These needs coincide with the needs of senior high school English teachers in English teaching. Therefore, the construction of high school students' English WeChat platform is required by teachers, students, and parents, which provides certain favorable conditions for the promotion of WeChat platform. WeChat platform is easy to operate, is powerful, timely pushes relevant information, and is a way worthy of promotion in high school English learning. 


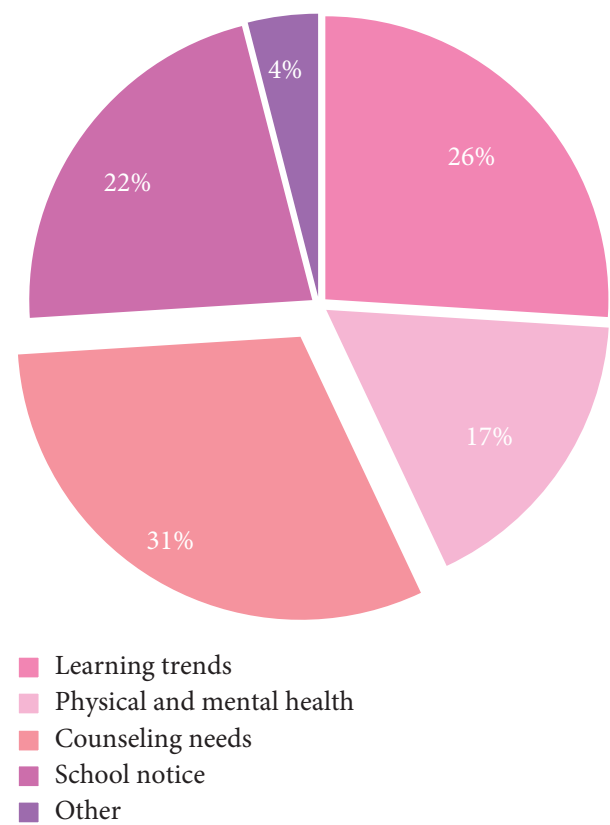

FIGURE 4: High school parents' English learning needs based on WeChat platform.

\section{Conclusion}

In response to the call for national education reforms, many colleges and universities have launched a raging education reform campaign for college English courses. However, the reformed college English classes are on the surface, but the problems of superficial thinking and inefficiency of students have not been fundamentally solved; the main reason is the lack of in-depth understanding and thinking of students, as well as the lack of autonomy and learning strategies and methods of deep learning. The emergence of mobile Internet has changed people's life style to a great extent and also spawned the rise of mobile social network. With one click, they can easily become the center of the world. Anyone can be the sender and receiver of information. Mobile Internet makes people's communication more comfortable than ever before. Since its release in 2011, WeChat has been loved and respected by Chinese people. As a social application software, it integrates social network, entertainment, marketing, payment and city services, and other functions, which will improve the living convenience of modern people. As a favorite of the new era, WeChat is a treasure in people's hands. Any communication of modern people cannot be separated from it.

College English learning in the context of information technology only enriches the presentation of knowledge and broadens the channels for acquiring knowledge. Most students are affected by the shortness and periodicity of classroom teaching time, and they rarely have in-depth thinking, leading to English. The learning efficiency is not high, the enthusiasm of extracurricular English learning is reduced, and even some students improperly use the core technology of the new learning tools and indulge in the virtual network world. Therefore, teachers can arouse the enthusiasm of students and improve their participation by designing a variety of teaching activities in the curriculum. Although the concept of mobile education or learning is still in development, it is uncertain about the future development. How students define the learning mode will determine the future development. Different participants still play an uncertain role in determining educational outcomes. The continuous progress of e-learning in the implementation process, such as the development of the ontology of learning objects, enables us to examine and challenge the knowledge composition and association mode. Similarly, the concept of knowledge and learning has also changed. The demand of organizing and guiding learning with scattered mobile learning content will also affect the concept of knowledge and learning. In the process of autonomous learning, students can form self-awareness in real time.

The ultimate goal of translation teaching is to enable students to learn various translation strategies and skills, cultivate high-quality applied translation talents, and have a sense of innovation and strong comprehensive ability. WeChat based interactive translation mobile teaching mode is a translation teaching concept based on constructivism theory, which can fully stimulate students' interest in learning and students' initiative and creativity in translation teaching and encourage students to turn from passive learning to active learning. This new teaching method overcomes the disadvantages of traditional translation teaching, creates an interactive teaching environment between teachers and students, and stimulates students' learning initiative. In view of the new trend of applicationoriented learning, the interactive teaching mode based on WeChat platform can more effectively cultivate talents with high quality, ability, and comprehensive development for the society.

\section{Data Availability}

This article does not cover data research. No data were used to support this study.

\section{Conflicts of Interest}

The authors declare that they have no conflicts of interest.

\section{Acknowledgments}

This work was supported by Research on Information Literacy Cultivation Mechanism of Foreign Language Teachers in Higher Vocational Colleges, Educational Science "13th Five Year Plan" Special Project of Shandong Province (Project no. 2020WGYB003).

\section{References}

[1] S. So, "Mobile instant messaging support for teaching and learning in higher education," The Internet and Higher Education, vol. 31, pp. 32-42, 2016.

[2] B. Zhang, "Research on framework design of English mobile teaching system in higher vocational colleges based on 
android platform," Boletin Tecnico/Technical Bulletin, vol. 55, no. 15, pp. 174-181, 2017.

[3] J. W. Hur, Y. W. Shen, U. Kale, and T. A. Cullen, "An exploration of pre-service teachers' intention to use mobile devices for teaching," International Journal of Mobile and Blended Learning, vol. 7, no. 3, pp. 1-17, 2015.

[4] J. E. Sánchez-García, J. A. Portilla-Figueras, S. Salcedo-Sanz, and S. Jiménez-Fernández, "2G/3G connect: an educational software for teaching $2 \mathrm{G} / 3 \mathrm{G}$ mobile communications to engineering students," Computer Applications in Engineering Education, vol. 23, no. 1, pp. 1-12, 2015.

[5] F. AlTameemy, "Mobile phones for teaching and learning," Journal of Educational Technology Systems, vol. 45, no. 3, pp. 436-451, 2017.

[6] D. Xu, "Research on new English mobile teaching mode under the impact of mobile Internet age," Open Journal of Social ences, vol. 7, no. 5, pp. 109-117, 2019.

[7] R. R. G. Gatbonton and G. R. Galang-Gatbonton, "Systematic review on the effects of mobile teaching applications in improving students physics performance," International Journal of Current Research, vol. 12, no. 1, pp. 9757-9761, 2020.

[8] A. Nawi, M. I. Hamzah, M. I. Hamzah, C. C. Ren, and A. H. Tamuri, "Adoption of mobile technology for teaching preparation in improving teaching quality of teachers," International Journal of Instruction, vol. 8, no. 2, pp. 113-124, 2015.

[9] Q. Wan, X. Yang, and G. Chen, "New scheduling algorithm for mobile teaching cloud resource push," International Journal of Emerging Technologies in Learning, vol. 13, no. 7, Article ID 17, 2018.

[10] W. A. R. W. M. Isa, I. M. Amin, and A. A. Ghani, "Investigating readiness of mobile teaching in rural areas: a qualitative content analysis," Advanced Science Letters, vol. 24, no. 1, pp. 600-602, 2018.

[11] S. Tu, X. Yan, K. Jie, M. Ying, and C. Huang, "WeChat: an applicable and flexible social app software for mobile teaching," Biochemistry and Molecular Biology Education, vol. 46, no. 5, pp. 555-560, 2018.

[12] W. A. R. W. M. Isa, I. M. Amin, and S. Z. Shabirin, "A mobile teaching value chain framework," Advanced Science Letters, vol. 24, no. 1, pp. 596-599, 2018.

[13] C. Wang, "Exploration and practice of college English mobile teaching mode under the WeChat environment," Revista de la Facultad de Ingenieria, vol. 32, no. 12, pp. 1028-1035, 2017.

[14] W. Zhang, W. Li, C. Zhang, D. M. Hanink, X. Li, and W. Wang, "Parcel-based urban land use classification in megacity using airborne LiDAR, high resolution orthoimagery, and Google Street View," Computers, Environment and Urban Systems, vol. 64, no. 4, pp. 215-228, 2017.

[15] A. Peris, M. Domingo, and F. Casacuberta, "Interactive neural machine translation," Computer Speech \& Language, vol. 45, pp. 201-220, 2016.

[16] S. Ananthakrishnan, D. N. Mehay, S. Hewavitharana, R. Kumar, M. Roy, and E. Kan, "Lightly supervised wordsense translation-error detection and resolution in an interactive conversational spoken language translation system," Machine Translation, vol. 29, no. 1, pp. 25-47, 2015.

[17] M. Domingo, Á. Peris, and F. Casacuberta, "Segment-based interactive-predictive machine translation," Machine Translation, vol. 31, no. 4, pp. 163-185, 2017.

[18] Z. Shi and G. Luo, "Application of WeChat teaching platform in interactive translation teaching," International Journal of Emerging Technologies in Learning, vol. 11, no. 9, Article ID 71, 2016.
[19] I. Kitouni, D. Benmerzoug, and F. Lezzar, "Smart agricultural enterprise system based on integration of Internet of things and agent technology," Journal of Organizational and End User Computing, vol. 30, no. 4, pp. 64-82, 2018.

[20] R. S. Bhadoria and N. S. Chaudhari, "Pragmatic sensory data semantics with service-oriented computing," Journal of Organizational and End User Computing, vol. 31, no. 2, pp. 22-36, 2019.

[21] L. Teng, Z. Fu, Q. Ma et al., "Interactive echocardiography translation using few-shot GAN transfer learning," Computational and Mathematical Methods in Medicine, vol. 2020, Article ID 1487035, 9 pages, 2020.

[22] R. Knowles, M. Sanchez-Torron, and P. Koehn, “A user study of neural interactive translation prediction," Machine Translation, vol. 33, no. 1-2, pp. 135-154, 2019.

[23] D. Ji, B. Ma, and N. Ye, "Prediction technology of translation query behavior in interactive machine translation," Journal of Computer Applications, vol. 26, no. 10, pp. 1127-1139, 2015.

[24] F. He, J. Li, B. Zhu, and G. Feng, "A new teaching mode improves the effect of comprehensive experimental teaching of genetics," Yi Chuan, vol. 37, no. 4, pp. 396-401, 2015.

[25] Y. Yao, "Application of flipped classroom teaching mode based on MOOC in modern educational technology teaching," Journal of Computational and Theoretical Nanoscience, vol. 14, no. 2, pp. 1075-1078, 2017.

[26] S. Wan, L. Qi, X. Xu, C. Tong, and Z. Gu, “Deep learning models for real-time human activity recognition with smartphones," Mobile Networks and Applications, vol. 25, pp. 743-755, 2020.

[27] R. Pun, "WeChat in the library: promoting a new virtual reference service using a mobile app," Library Hi Tech News, vol. 32, no. 6, pp. 9-11, 2015.

[28] D. Wang, Q. Zhong, and R. Kang, "The usability evaluation of a family rehabilitation guidance WeChat platform for parents with cerebral palsy children," Chinese Journal of Rehabilitation Medicine, vol. 33, no. 5, pp. 539-544, 2018. 